\title{
Actions of Camptothecin Derivatives on Larvae and Adults of the Arboviral Vector Aedes aegypti
}

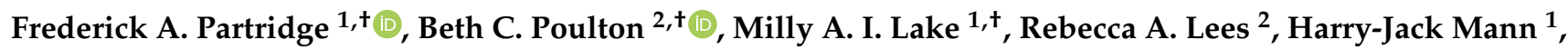 \\ Gareth J. Lycett ${ }^{2, *(\mathbb{D})}$ and David B. Sattelle ${ }^{1, *}$
}

1 Centre for Respiratory Biology, UCL Respiratory, Division of Medicine, University College London, London WC1E 6BT, UK; f.partridge@ucl.ac.uk (F.A.P.); milly.lake123@hotmail.co.uk (M.A.I.L.); hjmann3@gmail.com (H.-J.M.)

2 Liverpool School of Tropical Medicine, Pembroke Place, Liverpool L3 5QA, UK; Beth.Poulton@lstmed.ac.uk (B.C.P.); rebeccaannelees@gmail.com (R.A.L.)

* Correspondence: Gareth.Lycett@lstmed.ac.uk (G.J.L.); d.sattelle@ucl.ac.uk (D.B.S.)

+ These authors contribute equally to this work.

\section{check for} updates

Citation: Partridge, F.A.; Poulton, B.C.; Lake, M.A.I.; Lees, R.A.; Mann, H.-J.; Lycett, G.J.; Sattelle, D.B. Actions of Camptothecin Derivatives on Larvae and Adults of the Arboviral Vector Aedes aegypti. Molecules 2021, 26, 6226. https:// doi.org/10.3390/molecules26206226

Academic Editors:

Maria Chatzopoulou and

Angela Russell

Received: 9 September 2021

Accepted: 8 October 2021

Published: 15 October 2021

Publisher's Note: MDPI stays neutral with regard to jurisdictional claims in published maps and institutional affiliations.

Copyright: (c) 2021 by the authors. Licensee MDPI, Basel, Switzerland. This article is an open access article distributed under the terms and conditions of the Creative Commons Attribution (CC BY) license (https:// creativecommons.org/licenses/by/ $4.0 /)$.

\begin{abstract}
Mosquito-borne viruses including dengue, Zika, and Chikungunya viruses, and parasites such as malaria and Onchocerca volvulus endanger health and economic security around the globe, and emerging mosquito-borne pathogens have pandemic potential. However, the rapid spread of insecticide resistance threatens our ability to control mosquito vectors. Larvae of Aedes aegypti were screened with the Medicines for Malaria Venture Pandemic Response Box, an open-source compound library, using INVAPP, an invertebrate automated phenotyping platform suited to high-throughput chemical screening of larval motility. We identified rubitecan (a synthetic derivative of camptothecin) as a hit compound that reduced A. aegypti larval motility. Both rubitecan and camptothecin displayed concentration dependent reduction in larval motility with estimated $\mathrm{EC}_{50}$ of $25.5 \pm 5.0 \mu \mathrm{M}$ and $22.3 \pm 5.4 \mu \mathrm{M}$, respectively. We extended our investigation to adult mosquitoes and found that camptothecin increased lethality when delivered in a blood meal to A. aegypti adults at $100 \mu \mathrm{M}$ and $10 \mu \mathrm{M}$, and completely blocked egg laying when fed at $100 \mu \mathrm{M}$. Camptothecin and its derivatives are inhibitors of topoisomerase I, have known activity against several agricultural pests, and are also approved for the treatment of several cancers. Crucially, they can inhibit Zika virus replication in human cells, so there is potential for dual targeting of both the vector and an important arbovirus that it carries.
\end{abstract}

Keywords: insecticide; mosquito; Aedes; camptothecin; vector; rubitecan

\section{Introduction}

\subsection{Vector-Borne Diseases and Pandemics}

Humans have had to contend repeatedly with disease epidemics throughout history. Viruses such as Ebola, HIV, SARS-CoV-2, and Zika underscore the vulnerability of the human population to emerging pathogens. Furthermore, changes in our environment and society such as urbanization, increased travel, and climate change make epidemics more frequent and harder to control [1]. New and emerging infectious diseases, together with problems of antimicrobial resistance, are a challenge to our limited anti-infective medications and other tools for controlling diseases. To help to address this problem, the Medicines for Malaria Venture recently launched the Pandemic Response Box, an open-source drug discovery program, where laboratories around the world collaborate by screening a library of structurally diverse compounds selected for potential activity against infective and neglected diseases.

Diseases transmitted by arthropod vectors endanger people in many areas of the globe. These vector-borne pathogens include protozoa, such as Plasmodium, Trypanosoma, and Leishmania; nematodes, such as Onchocerca volvulus; as well as viruses, such as 
Chikungunya, dengue, yellow fever and Zika [2]. These diseases infect hundreds of millions of people, malaria kills 600,000 people each year, and Dengue kills 40,000 [3,4]. The 2015 Zika epidemic, where the virus, spread via the mosquito Aedes aegypti, was introduced into the Americas and then spread rapidly, infecting perhaps 500,000 people, underscores vividly the pandemic potential of vector-borne diseases [5].

\subsection{Control of Disease Vectors}

An important method for reducing the impact of vector-borne diseases is to target the vector. In the case of malaria, the incidence of clinical disease fell by $40 \%$ between 2000 and 2015, and it was estimated that over half of this reduction was due to insecticidetreated nets (ITNs) that target the disease-transmitting Anopheles adult mosquitoes [6]. However, ITNs have limitations, in particular the growing resistance to pyrethroids and other insecticides [7]. ITNs are less useful for the control of pathogens spread by A. aegypti, which include chikungunya, dengue, yellow fever, and Zika, as the mosquitoes prefer to feed outdoors at dawn and dusk. Larval source management is also important for vector control. This targets the larval stages of mosquitoes, which in the case of $A$. aegypti develop primarily in artificial, aquatic, urban environments, such as used tires, drains, and sewers, with the aim of reducing the prevalence of the adult vector. Application of mosquito larvicides is an important component of larval source management. The major classes of larvicides in current use are chemical insecticides, typically organophosphates, such as temephos, the sodium channel targeting pyrethroids, bacterial larvicides such as Bacillus thuringiensis toxin, which impact gut cell membrane permeability, and insect growth regulators, like diflubenzuron, which block development of the insect.

However, resistance to current larvicides is a problem, with, for example, A. aegypti resistance to temephos, the major organophosphate larvicide, widespread in Brazil [8]. Whilst pyrethroid use in water sources is now prohibited because of toxicity to fish [9], pyrethroids used in agriculture are known to leach into aquatic ecosystems. Even at the low concentrations observed, early larval exposure is thought to exacerbate the development of pyrethroid-resistance in adults [10] in areas where mosquito control is needed, [11] and also that such larval stressors can impact the adult immune response [12]. Identification and development of new larvicidal agents thus remains a priority.

\subsection{Open Science and the MMV Pandemic Response Box}

Open science is an alternative way of doing science that aims to open up the research process, making innovation more efficient by the timely sharing of data, creation of collaborative communities, and avoiding duplication of effort $[13,14]$. An example is the Medicines for Malaria Venture (MMV) Pandemic Response Box project, an open-source distributed drug-discovery project, where a compound library is screened in multiple laboratories in a diversity of assays. The goal is identification of small molecules with potential for development to control emerging diseases with pandemic potential. It follows on from the successful MMV Malaria and Pathogen Box projects [15,16].

We developed a screening platform, INVAPP, that quantifies movement or growth of an organism in microplates [17]. This system was originally developed to search for new anthelmintics [18-21]. We recently adapted this platform for screening mosquito larvae of various species [22]. Here, we report the use of the INVAPP platform as part of the Medicines for Malaria Venture Pandemic Response Box project by screening for new anti-mosquito compounds that could be useful in the control of vector-borne diseases.

\section{Results}

The actions on A. aegypti larval motility of each of the 400 compounds in the Pandemic Response Box was measured using the INVAPP system at 0,2 , and $24 \mathrm{~h}$ timepoints. Figure 1a shows the effects of each compound tested, as well as DMSO-only and deltamethrin controls, on motility at $2 \mathrm{~h}$ and $24 \mathrm{~h}$. Deltamethrin at $10 \mu \mathrm{M}$ effectively paralyses the larvae, but some compounds in the library showed some reduction in larval 
motility. The data for all 400 compounds in the MMV Pandemic Response Box are provided in Table S1. Fourteen compounds, highlighted in blue in Figure 1a, that reduced motility at $2 \mathrm{~h}$ and / or $24 \mathrm{~h}$ to less than $40 \%$ of DMSO-only controls were selected as candidate hits and taken forward to a secondary screen. These compounds were retested at $10 \mu \mathrm{M}$ in a secondary screen (Figure $1 \mathrm{~b}$ ), where the effects on motility after $24 \mathrm{~h}$ of treatment were analysed. A one-way ANOVA test found a significant effect of compound treatment on motility $\left[\mathrm{F}(15,144)=3.891 p=7.86 \times 10^{-6}\right.$. Dunnett's test was then used to compare each compound with the DMSO-only control. Deltamethrin (the positive control, $p=0.027$ ) and rubitecan $(p=0.041)$ showed a significant difference in motility compared to that of the control. The structure of rubitecan is shown in Figure 1c. Rubitecan is a topoisomerase inhibitor, originally developed as a potential therapy for various cancers [23].

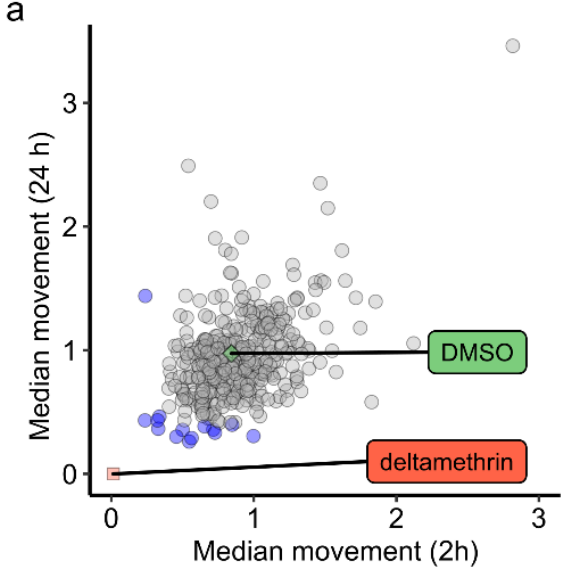<smiles>CCC1(O)C(=O)OCc2c1cc1n(c2=O)Cc2cc3c([N+](=O)[O-])cccc3nc2-1</smiles>

b

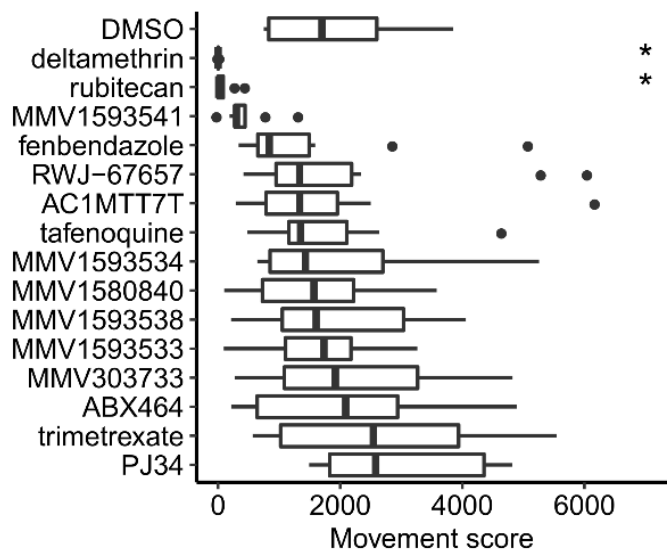

Figure 1. Screening 400-compound MMV Pandemic Response Box chemical library in an A. aegypti larval motility assay led to identification of hit compound rubitecan. (a) Primary screen. Each point is effect of one compound on motility at $2 \mathrm{~h}$ and $24 \mathrm{~h}$, normalized to motility at $0 \mathrm{~h}$ timepoint. $n=3$. DMSO-only and deltamethrin were negative and positive control compounds, respectively. Blue points indicate 14 compounds that were selected as candidate hit compounds. (b) Secondary screen, showing effects of each compound on motility after $24 \mathrm{~h} . n=10 .{ }^{*}$ indicates $p<0.05$ compared to that of DMSO-only control (Dunnett's test). Dots indicate individual outlying datapoints beyond the boxplot whiskers. (c) Structure of rubitecan.

Having pursued these initial studies using library material stored as DMSO stocks, it was important to confirm the activity of rubitecan in the larval motility assay using solutions freshly prepared from solid material. Rubitecan is a synthetic derivative of camptothecin (Figure 2b), an alkaloid isolated from Camptotheca acuminata, a tree native to China. We also wanted to determine the activity of camptothecin itself, as well as topotecan (Figure 2c), another camptothecin derivative, which is approved for the treatment of cervical, ovarian, and small cell lung cancers. These compounds were tested in the same $24 \mathrm{~h}$ treatment larval motility assay at $100 \mu \mathrm{M}$. These results are shown in Figure 2a. A one-way ANOVA showed a significant effect of treatment, $\mathrm{F}(3,16)=22.0 p=6.32 \times 10^{-6}$. Dunnett's test was then used to compare each treatment with the DMSO-only control. Camptothecin $\left(p=8.5 \times 10^{-6}\right)$, rubitecan $\left(p=8.3 \times 10^{-6}\right)$, and topotecan $(p=0.00087)$ all showed a significant difference in motility compared to that of the control, although the 
effect on motility was less in the case of topotecan. Examples of mosquito morphology and movement in wells treated with each compound are presented in Video S1. A time-lapse montage is also shown in Figure 2d.

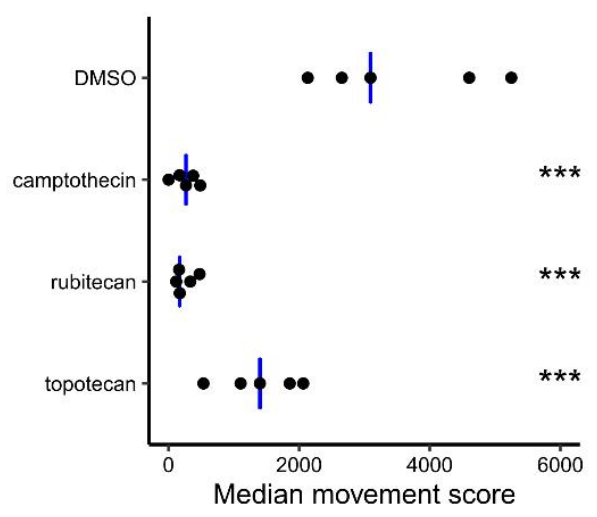<smiles>CC[C@@]1(O)C(=O)OCc2c1cc1n(c2=O)Cc2cc3ccccc3nc2-1</smiles>

C<smiles>CC[C@@]1(O)C(=O)OCc2c1cc1n(c2=O)Cc2cc3c(CN(C)C)c(O)ccc3nc2-1</smiles>

d

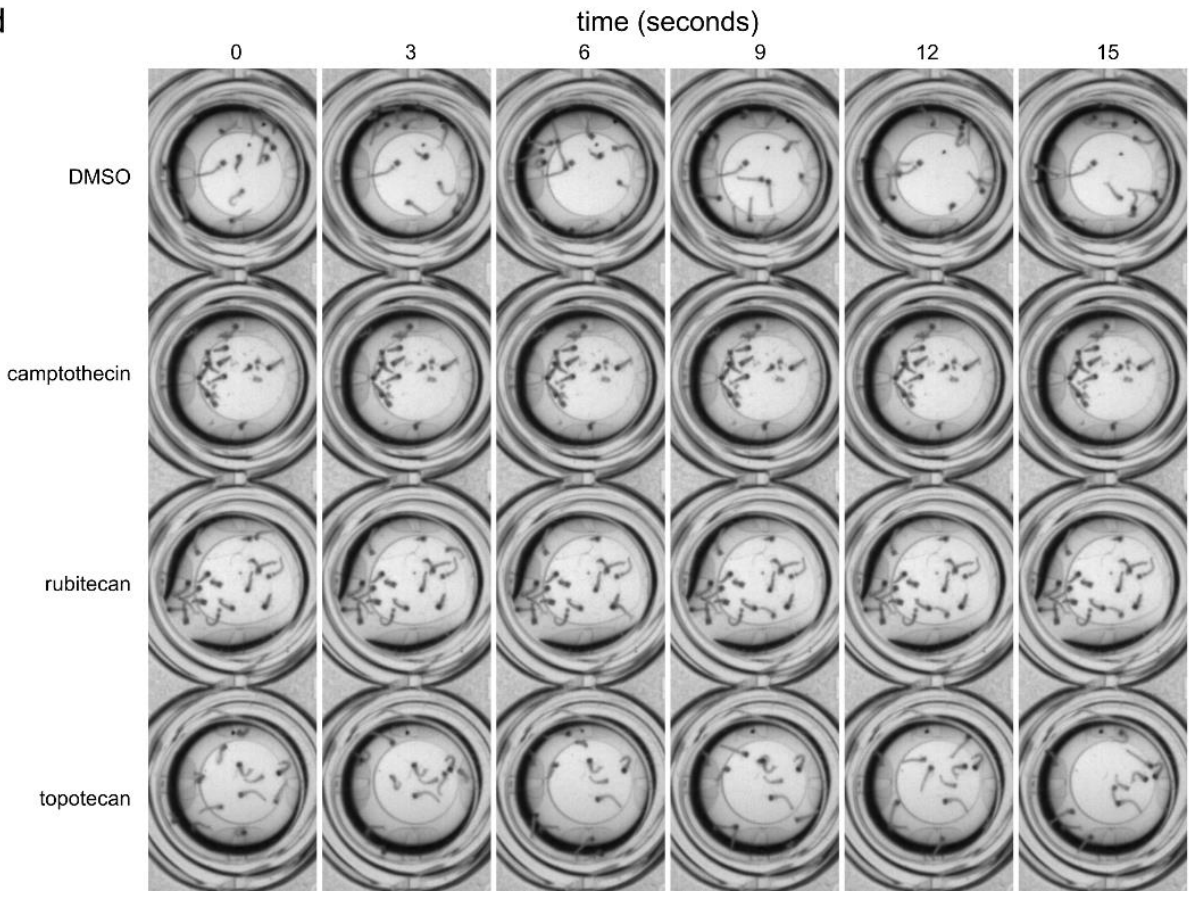

Figure 2. Retesting actions on larval motility of rubitecan and related compounds prepared freshly from solid material. (a) Retesting in A. aegypti larval motility assay of rubitecan prepared from solid material and testing of two related compounds, camptothecin, and topotecan, also prepared from solid material. Compounds were screened at $100 \mu \mathrm{M}$. Black dots indicate the within-batch median movement score for each of $n=5$ biological replicates (batches of independently hatched mosquito larvae). Blue bars indicate between-batch median. A one-way ANOVA showed a significant effect of compound treatment $\mathrm{F}(3,16)=22.0 p=6.32 \times 10^{-6}$. A posthoc Dunnett's test was then used to compare compound treatments with the DMSO-only control. ${ }^{* * *}$ indicates $p<0.001$. (b) Structure of camptothecin. (c) Structure of topotecan. (d) Time-lapse montage of representative assay wells. This is presented as video in Video S1.

We next wanted to determine the concentration dependence of the larvicidal effect of the hit compounds. Concentration-response curves were obtained using the same larval motility assay (Figure 3a,b). Curves were fitted using the 4 -factor log-logistic model. 
The $\mathrm{EC}_{50}$ of camptothecin was estimated to be $22.3 \pm 5.4 \mu \mathrm{M}$, and that of rubitecan was estimated to be $25.5 \pm 5.0 \mu \mathrm{M}$.
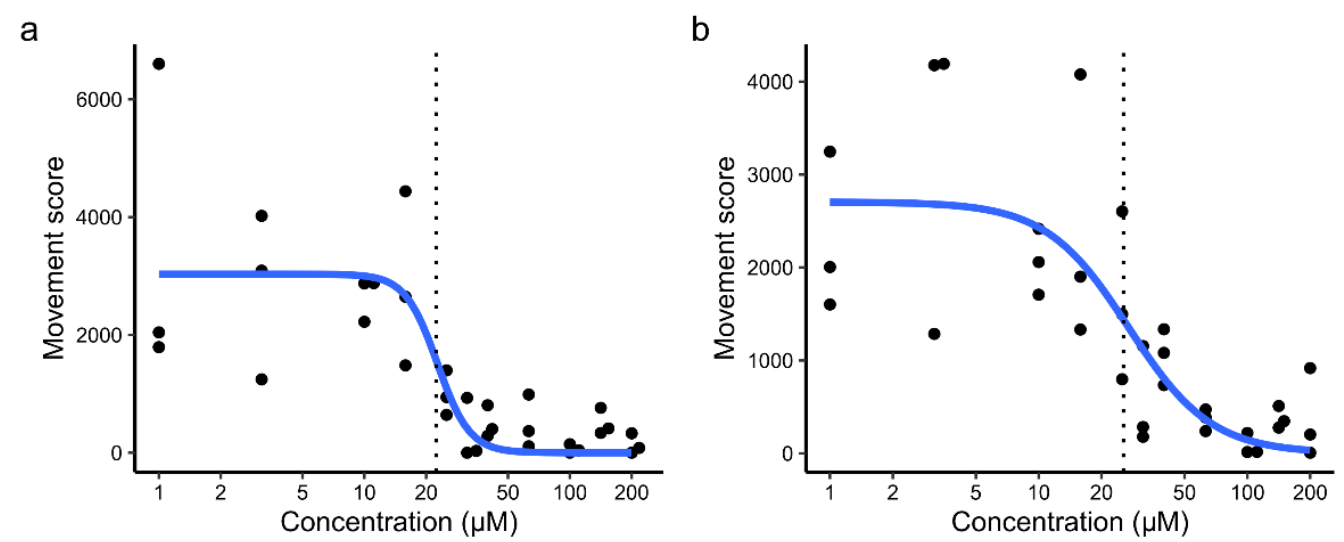

Figure 3. Concentration dependence of actions on larval motility of (a) camptothecin and (b) rubitecan. Curve fitted using the 4-factor log-logistic model. $n=3$. Each point shows the measured movement score for a single well of mosquito larvae treated with the indicated concentration. Dotted lines indicate $\mathrm{EC}_{50}$.

Finally, we investigated the usefulness of camptothecin to target adult mosquitoes. Attempts to kill adult mosquitoes in tarsal assays $(100 \mu \mathrm{M}, 30 \mathrm{~min})$ and in sugar meals (100 $\mu \mathrm{M}$, daily) did not indicate a strong phenotype (data not shown). Females were fed with blood containing camptothecin according to the regimen outlined in Figure $4 \mathrm{a}$, and mortality was recorded at each time point. The results are shown in Figure $4 b$,c. There was a significant difference in lethality between treatment groups as determined by one-way ANOVA $\left(\mathrm{F}(4,10)=40.72, p=3.7 \times 10^{-6}\right)$. A Tukey posthoc test $(95 \% \mathrm{CI} \pm 25.7)$ revealed significant increased mortality in females fed $100 \mu \mathrm{M}$ camptothecin compared to that of those fed no compound $\left(+80.0 \%, p=9.8 \times 10^{-6}\right), 1 \%$ DMSO $\left(+76.7 \%, p=1.45 \times 10^{-5}\right)$ and $10 \mu \mathrm{M}$ camptothecin $(+41.2 \%, p=0.0026)$ and in those fed $10 \mu \mathrm{M}$ camptothecin compared to that of those fed no compound $(+38.8 \%, p=0.004)$ and $0.01 \%$ DMSO $(+39.4 \%, p=0.0036)$.

We also measured the number of eggs laid per adult mosquito (Figure $4 \mathrm{~d}$ ), the number of larvae that hatched per adult mosquito (Figure 4e), and the proportion of eggs that hatched for each treated adult mosquito (Figure 4f). Significant differences in the number of eggs laid were also observed between treatment groups using a one-way ANOVA $\left(\mathrm{F}(4,131)=12.52, p=1.16 \times 10^{-8}\right)$. Females exposed to $100 \mu \mathrm{M}$ camptothecin did not lay any eggs. A Tukey post hoc $(95 \% \mathrm{CI} \pm 22.19)$ indicated significant differences in the number of eggs laid by females fed $100 \mu \mathrm{M}$ camptothecin and females fed no compound $\left(-53.9\right.$ eggs, $\left.p<1 \times 10^{-7}\right), 1 \%$ DMSO $\left(-48.13\right.$ eggs, $\left.p=2 \times 10^{-7}\right)$, and $10 \mu \mathrm{M}$ camptothecin $\left(-40.1\right.$ eggs, $\left.p=1.81 \times 10^{-5}\right)$.

The number of larvae that hatched also differed significantly by treatment using a one-way ANOVA $\left(\mathrm{F}(4,131)=9.846, p=5.38 \times 10^{-7}\right)$, but the significant reductions observed with a posthoc Tukey $(95 \% \mathrm{CI} \pm 18.9)$ were between females fed $100 \mu \mathrm{M}$ camptothecin and females fed no compound ( -38.7 larvae, $\left.p=9 \times 10^{-7}\right)$, 1\% DMSO ( -37.4 larvae, $\left.p=2.3 \times 10^{-6}\right)$, and $10 \mu \mathrm{M}$ camptothecin $(-23.7$ larvae, $p=0.00632)$.

No significant differences in egg laying and number of larvae hatched were observed between females fed $10 \mu \mathrm{M}$ camptothecin and controls, and no significant differences in larval hatch percentage between treatments were detected using a one-way ANOVA $(\mathrm{F}(3,87)=2.687, p=0.0514)$. 
a
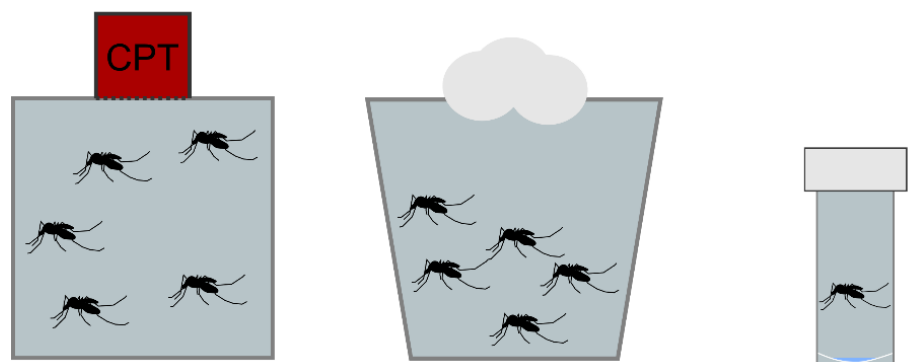

20 mins blood

$\longrightarrow \quad 96$ hours feed \pm CPT

b

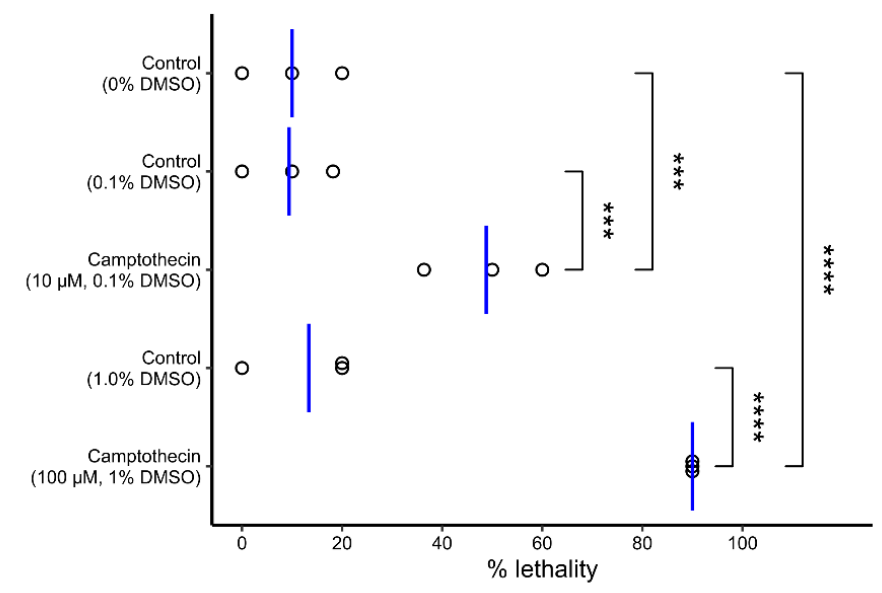

d
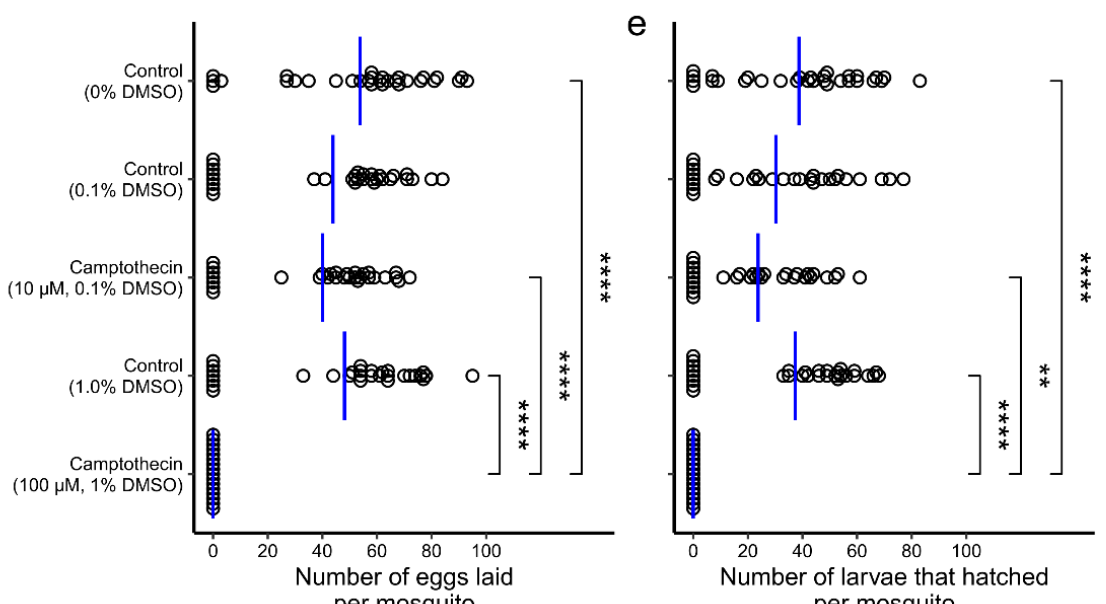

per mosquito
$0-96 \mathrm{~h}$

96-120 h survived

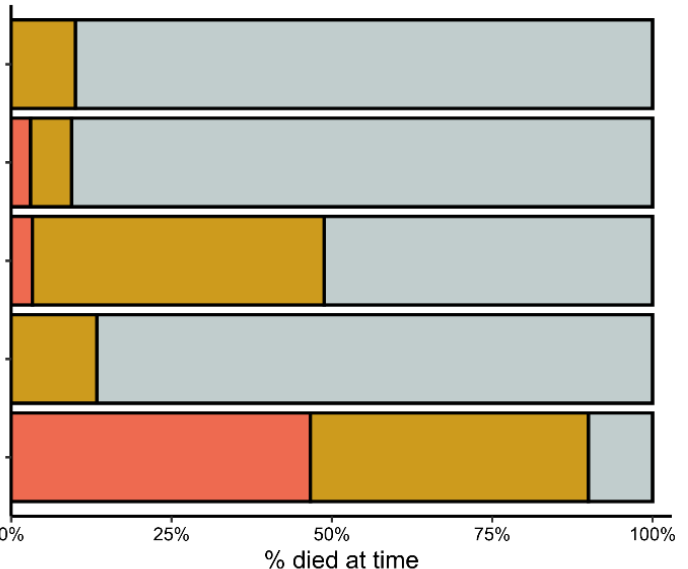

$\%$ died at time

Figure 4. Assessing effects of camptothecin on adult A. aegypti. (a) Diagrammatic representation of methodological process. (b) Effect of camptothecin concentration on percentage lethality across entire experiment-each point represents percentage lethality in each experimental replicate $(n=3)$. (c) Effect of camptothecin concentration on percentage of total females which died indicating period during experiment when death occurred (red $=0-96 \mathrm{~h}$, yellow $=96-120 \mathrm{~h}$ ) or survived to end of the experiment (grey). (d) Effect of camptothecin concentration on number of eggs laid per individual mosquito. Each point represents number of eggs laid by an individual female ( $n=30$ per condition). (e) Effect of camptothecin concentration on number of larvae hatched per individual mosquito. Each point represents number of larvae hatched from an individual female ( $n=30$ per condition). (f) Effect of camptothecin concentration on hatch percentage. Each point represents the proportion of eggs which hatched for each individual female ( $n=30$ per condition). No females laid eggs and so no hatch percentage could be calculated where $(\mathrm{n} / \mathrm{a})$ is noted. Vertical blue lines indicate mean and significance as determined using a Tukey posthoc assessment is indicated as follows on $(\mathbf{b}, \mathbf{d}-\mathbf{f})\left(^{* * * *}<0.0001,{ }^{* * *}<0.001,{ }^{* *}<0.01\right.$, 'absence of bracket' $\left.>0.05\right)$. 


\section{Discussion}

\subsection{Camptothecin Derivatives as Insecticides}

In this study, we screened the MMV Pandemic Response box in a mosquito larval motility assay, and identified that camptothecin, as well as the derivatives rubitecan and topotecan, had antilarval activity against $A$. aegypti. This observation is concordant with previous observations of camptothecin-related compounds having insecticidal properties, although no compound from this chemotype reached the market for this use [24]. Indeed, a crude extract of C. acuminata was traditionally used in China to control pests [25]. Camptothecin was first shown to have chemo-sterilant activity against the housefly [26], and camptothecin or derivative compounds are active against agricultural pests [27,28].

This study used larvae $24 \mathrm{~h}$ after commencement of hatching, as these small larvae are suited for high-throughput larvicide screening due to their compatibility with 96-well plates and dispensing by pipette or microplate filler. Larvicidal activity may differ between different instars [29]. Therefore, further investigation of camptothecin derivatives should utilize additional larval stages.

\subsection{Camptothecin Derivatives as Antivirals}

Camptothecin derivatives, including topotecan and irinotecan, were approved for the treatment of various cancers. They are inhibitors of topoisomerase I (TOP1), an enzyme important for DNA replication and repair, as well as transcription. Because of this mechanism, camptothecin derivatives were investigated as potential antivirals [30]. Of particular note, camptothecin or derivatives have shown activity in cells against herpes simplex virus type 2 [31] and enterovirus 71 [32]. Interestingly, camptothecin also suppresses the host response to viral and bacterial infection and protected mice in a model of lethal inflammation [33].

The dual insecticidal and antiviral activities of camptothecin-like compounds is intriguing and may motivate further study. Zika virus is transmitted vertically within the $A$. aegypti population $[34,35]$, and vertical transmission in the mosquito host also occurs with many other flaviviruses. Furthermore, A. aegypti larvae can acquire Zika virus from the environment, such as sewage containing the virus, and are able to transmit the virus to mammalian hosts [36]. Camptothecin, 1-hydroxycamptothecin, irinotecan, and topotecan were shown to inhibit Zika virus replication in human cells [37]. Therefore, a camptothecinbased antilarval compound may also have a role to play in reducing viral transmission by acting on the virus in the insect.

\subsection{Safety for Larvicidal Use}

Camptothecin and related compounds are cytotoxic to mammalian cells, which underpins their use in chemotherapy. We do not underestimate the challenge of deploying such compounds in the environment as larvicides. The target of camptothecin, topoisomerase $\mathrm{I}$, is a highly conserved enzyme, with all the residues that contact the drug in a topotecan/human topoisomerase I crystal structure [38] conserved across insects (Figure 5). This likely limits our ability to make more insect-specific derivative molecules by exploiting differences in target binding. 
Human TOP1 P11387

Aedes aegypti Q17HT9

Anopheles gambiae Q7QH57

Acyrthosiphon pisum ACYPI000854-PA

Apis mellifera A0A088A1M3

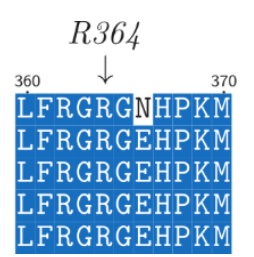

K532, D533

$530 \downarrow \downarrow$ EFDFLGKDSIRYYNK̈V VFDFLGKDSIRYYNEV VFDFLGKDSIRYYNEV VFDFLGKDSIRYYNEV VFDFLGKDSIRYYNEV
N722, Y723

$720 \downarrow \downarrow$

730

GT LIV LPRITVA

LGTSKLNYLDPRISVA

LGT SKLNYLDPR ISVAW

LGTSKLNYLDPR ISVAW

LGTSKLNYLDPRITVAW

Figure 5. Conservation of camptothecin binding site in topoisomerase I between insects and vertebrates. Residues of TOP1 that make direct contact with topotecan in a crystal structure [38] are highlighted above alignment.

However, camptothecin itself did not find use in humans due to problems with pharmacokinetics. These problems include limited water solubility, rapid ring opening in plasma, where the active lactone is converted to an inactive carboxylate in plasma, and variable bioavailability, preventing oral dosing of camptothecin $[39,40]$. The route to clinical approval involved the development of water-soluble analogues of camptothecin, of which the first to be approved was topotecan, for intravenous administration, in 1996. Topotecan has appreciable oral bioavailability, around 35-40\% [41], and 10-fold greater stability as the active lactone form in human blood compared to that of camptothecin [42]. Topotecan was approved for oral administration in 2007. Interestingly, in our mosquito assay, topotecan was much less active than camptothecin. This suggests that there is potential for identification of camptothecin derivatives that have acceptable safety profiles by exploiting pharmacokinetic differences between target insects and people, such as drug access or metabolism. Organophosphates, currently important mosquito larvicides, have a poor safety record. Organophosphate poisoning, either due to occupational exposure or self-harm, kills an estimated 200,000 people each year [43]. This underscores the need to develop safer effective mosquito larvicides.

\subsection{Use as an Adulticide}

Females fed $100 \mu \mathrm{M}$ and $10 \mu \mathrm{M}$ camptothecin in a blood meal demonstrated significantly increased mortality ( $90 \%$ and $48.8 \%$ respectively) across the experiment compared to that of controls. Absolute blocking of egg laying was observed in females fed $100 \mu \mathrm{M}$ camptothecin but no effect on egg laying, larval hatching, or hatch percentage was observed for those fed $10 \mu \mathrm{M}$ and many laid eggs prior to death during the experiment. This suggests that a concentration between 10 and $100 \mu \mathrm{M}$ camptothecin would be required to impact the reproductive ability of $A$. aegypti.

TOP1 analogues are found in all eukaryotes and appear to be an essential enzyme during development in a wide variety of animals. During the process of DNA replication and transcription TOP1 is responsible for relaxing supercoiled DNA [44]. Knockouts of TOP1 are embryonically lethal in Mus musculus [45] and Drosophila melanogaster (Zhang, CX et al., 2000). TOP1 was demonstrated to be essential for larval and pupal growth, oogenesis and embryogenesis in D. melanogaster [46]. Larvae are developing and undergoing more growth, cell replication, and differentiation than in adults, which explains the greater susceptibility of larval stages that we observed.

Is it feasible to propose the use of a camptothecin derivative to target adult mosquitoes? We note the high concentrations of camptothecin (10 or $100 \mu \mathrm{M})$ that needed to be delivered in a blood meal to impact adult survival. Ivermectin is capable of killing Anopheles mosquitoes after they bite a human host who took the drug [47]. However the concentration of ivermectin required for lethality is in the low nanomolar range [48], and it is well tolerated and is used widely for mass drug administration (MDA) control of helminths in areas where mosquitoes and malaria are a problem [49]. We already discussed the potential antiviral use of camptothecin derivatives. Clearly compounds with improved potency against mosquitoes, as well as a much-improved safety profile, would need to be developed to be useful as anti-viral agents in humans with the additional benefit of controlling blood-feeding insect vectors. 


\section{Materials and Methods}

\subsection{Larval Motility Assay}

A. aegypti egg papers were hatched in $500 \mathrm{~mL}$ pond salt solution (Blagon) supplemented with a quarter of a crushed $500 \mathrm{mg}$ yeast tablet (Holland and Barrett), at $25^{\circ} \mathrm{C}$. After 18-24 h, larvae were collected with a $100 \mu \mathrm{m}$ cell strainer, and diluted in pond salt solution to approximately 10 larvae per $100 \mu \mathrm{L}$.

Compounds were screened in 96-well plates. $100 \mu \mathrm{L}$ of the larvae suspension was added to each well. There were approximately 10 larvae per well. The number of larvae per well did vary somewhat due to the stochastic nature of pipetting larvae from a stirred solution. However, the INVAPP system quantifies the overall movement within a well so was able to identify larvicidal compounds despite this variability.

For the primary screen using the Pandemic Response Box, the compound concentration in the assay was $10 \mu \mathrm{M}, 1 \% v / v$ DMSO. Negative control ( $1 \% v / v$ DMSO) and positive control wells ( $10 \mu \mathrm{M}$ deltamethrin, $1 \% v / v$ DMSO) were present on each assay plate. For the secondary screen, selected compounds were sourced from the original library material and screened at $10 \mu \mathrm{M}, 1 \% v / v \mathrm{DMSO}$, with positive and negative controls as in the primary screen.

Movies were recorded and motility quantified using the INVAPP system [17,22]. Movies of 200 frames at $100 \mathrm{~ms}$ intervals were recorded immediately after the larval suspension was pipetted into the assay plates (nominally $0 \mathrm{~h}$ timepoint) and again after $2 \mathrm{~h}$ and $24 \mathrm{~h}$.

The Pandemic Response Box was a gift from the Medicines for Malaria Venture. For the primary screen, each well was normalized for inhomogeneity in the number of mosquitoes dispensed per well by dividing the motility score at $2 \mathrm{~h}$ or $24 \mathrm{~h}$ by that of the same well at $0 \mathrm{~h}$. The library was screened three times using independently prepared batches of mosquito larvae. Hit compounds were chosen where the median movement score at $2 \mathrm{~h}$ and/or $24 \mathrm{~h}$ was $<40 \%$ of the same wells at $0 \mathrm{~h}$.

The secondary screen was carried out on two occasions, each time with five independent assay plates $(n=10)$. The $24 \mathrm{~h}$ time point was analysed. For each assay plate, the median movement score of the negative and positive control replicate wells was calculated and used for subsequent analysis. The effect of compound treatment was determined using a one-way ANOVA test, and the identity of active compounds was then determined by Dunnett's test, in comparison with that of the DMSO negative control.

Rubitecan, and the related compounds camptothecin and topotecan, were then retested using solid material at an assay concentration of $100 \mu \mathrm{M}$. Camptothecin (208925), rubitecan (9-nitrocamptothecin, R3655) and topotecan hydrochloride (T2705) were obtained from Merck Life Science.

Concentration response curves were fitted using the R package drc [50].

\subsection{Adult Treatment Assays}

$10 \mathrm{mM}$ camptothecin stock was made in DMSO. Blood containing $100 \mu \mathrm{M}$ and $10 \mu \mathrm{M}$ camptothecin, $1 \%$ and $0.1 \%$ DMSO (as solvent controls, respectively), and no additions (no DMSO control) were fed to 3 pools of 10 New Orleans adult (5-7 days old) females for each compound-concentration using a hemotek system. Adults were allowed $20 \mathrm{~min}$ to feed, and any unfed adults were removed. Adults were maintained in paper cups supplied ad libitum with $10 \%$ sugar solution on cotton wool.

At 4 days postblood-feeding, the surviving individuals (mortality recorded-0-96 h) were transferred to a $5 \mathrm{~mL}$ bijou tube with a $2.5 \mathrm{~cm}$ Whatman paper no. 3 disk soaked in water pushed to the bottom to form a slight concave shape with a small pool of water for egg laying. Females were held in these tubes for $24 \mathrm{~h}$ to permit laying after which females were removed (mortality recorded: $96-120 \mathrm{~h}$ ).

Lids were removed from tubes that were batch covered with netting to permit drying of the filter paper and eggs but preventing undesired egg laying by other mosquitoes. Seven days later, $2 \mathrm{~mL}$ of yeast suspension (1 yeast tablet dissolved/suspended in $500 \mathrm{~mL}$ 
water) was added to each tube to stimulate larval hatching and netting was replaced. Two days later, the number of larvae hatched, and number of eggs laid were counted.

Differences in lethality, the number of eggs and larvae, and the percentage of laid eggs that hatched were assessed with a Tukey HSD posthoc test in R.

Supplementary Materials: The following are available online. Video S1: Recording of A. aegypti larvae treated with camptothecin-derivatives at $100 \mu \mathrm{M}$, or the DMSO-only control, after $24 \mathrm{~h}$. Images were recorded every $100 \mathrm{~ms}$, Table S1: Effect of all MMV Pandemic Box compounds on A. aegypti larval motility after 2 and $24 \mathrm{~h}$ of treatment in the primary screen.

Author Contributions: Conceptualization, F.A.P., B.C.P., G.J.L., D.B.S.; formal analysis, F.A.P., B.C.P., H.-J.M.; investigation, F.A.P., B.C.P., M.A.I.L., R.A.L.; supervision, G.J.L. and D.B.S.; writing—original draft, F.A.P. and B.C.P.; writing-review \& editing, F.A.P., B.C.P., G.J.L., D.B.S. All authors have read and agreed to the published version of the manuscript.

Funding: This research was funded by Medical Research Council (UK) grant MR/N024842/1 and Medical Research Council (UK) studentship MR/P016197/1.

Institutional Review Board Statement: Not applicable.

Informed Consent Statement: Not applicable.

Data Availability Statement: Data for the compound screen are provided in Table S1.

Acknowledgments: We thank Medicines for Malaria Venture for designing and supplying the Pandemic Response Box.

Conflicts of Interest: The authors declare no conflict of interest. The funders had no role in the design of the study; in the collection, analyses, or interpretation of data; in the writing of the manuscript, or in the decision to publish the results.

Sample Availability: Camptothecin, rubitecan and topotecan are widely commercially available. Samples of other compounds found in the MMV Pandemic Response Box are not available from the authors but are distributed by Medicines for Malaria Venture (https://www.mmv.org/).

\section{References}

1. Bedford, J.; Farrar, J.; Thekweazu, C.; Kang, G.; Koopmans, M.; Nkengasong, J. A new twenty-first century science for effective epidemic response. Nature 2019, 575, 130-136. [CrossRef]

2. Shaw, W.R.; Catteruccia, F. Vector biology meets disease control: Using basic research to fight vector-borne diseases. Nat. Microbiol. 2019, 4, 20-34. [CrossRef]

3. GBD 2017 Disease and Injury Incidence and Prevalence Collaborators. Global, regional, and national incidence, prevalence, and years lived with disability for 354 diseases and injuries for 195 countries and territories, 1990-2017: A systematic analysis for the Global Burden of Disease Study 2017. Lancet 2018, 392, 1789-1858. [CrossRef]

4. GBD 2017 Causes of Death Collaborators. Global, regional, and national age-sex-specific mortality for 282 causes of death in 195 countries and territories, 1980-2017: A systematic analysis for the Global Burden of Disease Study 2017. Lancet 2018, 392, 1736-1788. [CrossRef]

5. Musso, D.; Ko, A.I.; Baud, D. Zika virus infection-After the pandemic. N. Engl. J. Med. 2019, 381, 1444-1457. [CrossRef] [PubMed]

6. Bhatt, S.; Weiss, D.J.; Cameron, E.; Bisanzio, D.; Mappin, B.; Dalrymple, U.; Battle, K.; Moyes, C.L.; Henry, A.; Eckhoff, P.A.; et al. The effect of malaria control on Plasmodium falciparum in Africa between 2000 and 2015. Nature 2015, 526, 207-211. [CrossRef]

7. Hemingway, J.; Ranson, H.; Magill, A.; Kolaczinski, J.; Fornadel, C.; Gimnig, J.; Coetzee, M.; Simard, F.; Roch, D.K.; Hinzoumbe, C.K.; et al. Averting a malaria disaster: Will insecticide resistance derail malaria control? Lancet 2016, 387, 1785-1788. [CrossRef]

8. Valle, D.; Bellinato, D.F.; Viana-Medeiros, P.F.; Lima, J.B.P.; Martins Junior, A. de J. Resistance to temephos and deltamethrin in Aedes aegypti from Brazil between 1985 and 2017. Mem. Inst. Oswaldo Cruz 2019, 114, e180544. [CrossRef] [PubMed]

9. Farag, M.R.; Alagawany, M.; Bilal, R.M.; Gewida, A.G.A.; Dhama, K.; Abdel-Latif, H.M.R.; Amer, M.S.; Rivero-Perez, N.; Zaragoza-Bastida, A.; Binnaser, Y.S.; et al. An overview on the potential hazards of pyrethroid insecticides in fish, with special emphasis on cypermethrin toxicity. Animals 2021, 11, 1880. [CrossRef] [PubMed]

10. Churcher, T.S.; Lissenden, N.; Griffin, J.T.; Worrall, E.; Ranson, H. The impact of pyrethroid resistance on the efficacy and effectiveness of bednets for malaria control in Africa. eLife 2016, 5, e16090. [CrossRef]

11. Diabate, A.; Baldet, T.; Chandre, F.; Akoobeto, M.; Guiguemde, T.R.; Darriet, F.; Brengues, C.; Guillet, P.; Hemingway, J.; Small, G.J.; et al. The role of agricultural use of insecticides in resistance to pyrethroids in Anopheles gambiae s.l. in Burkina Faso. Am. J. Trop. Med. Hyg. 2002, 67, 617-622. [CrossRef] 
12. Hauser, G.; Koella, J.C. Larval exposure to a pyrethroid insecticide and competition for food modulate the melanisation and antibacterial responses of adult Anopheles gambiae. Sci. Rep. 2020, 10, 1364. [CrossRef] [PubMed]

13. Partridge, F.A.; Forman, R.; Bataille, C.J.R.; Wynne, G.M.; Nick, M.; Russell, A.J.; Else, K.J.; Sattelle, D.B. Anthelmintic drug discovery: Target identification, screening methods and the role of open science. Beilstein J. Org. Chem. 2020, 16, 1203-1224. [CrossRef] [PubMed]

14. Todd, M.H. Six Laws of open source drug discovery. ChemMedChem 2019, 14, 1804-1809. [CrossRef] [PubMed]

15. Van Voorhis, W.C.; Adams, J.H.; Adelfio, R.; Ahyong, V.; Akabas, M.H.; Alano, P.; Alday, A.; Resto, Y.A.; Alsibaee, A.; Alzualde, A.; et al. Open source drug discovery with the malaria box compound collection for neglected diseases and beyond. PLoS Pathog. 2016, 12, e1005763. [CrossRef] [PubMed]

16. Veale, C.G.L. Unpacking the pathogen box-An open source tool for fighting neglected tropical disease. ChemMedChem 2019, 14, 386-453. [CrossRef] [PubMed]

17. Partridge, F.A.; Brown, A.E.; Buckingham, S.D.; Willis, N.J.; Wynne, G.M.; Forman, R.; Else, K.J.; Morrison, A.A.; Matthews, J.B.; Russell, A.J.; et al. An automated high-throughput system for phenotypic screening of chemical libraries on C. elegans and parasitic nematodes. Int. J. Parasitol. Drugs Drug Resist. 2018, 8, 8-21. [CrossRef]

18. Hurst, R.J.; Hopwood, T.; Gallagher, A.L.; Partridge, F.A.; Burgis, T.; Sattelle, D.B.; Else, K.J. An antagonist of the retinoid X receptor reduces the viability of Trichuris muris in vitro. BMC Infect. Dis. 2014, 14, 520. [CrossRef]

19. Partridge, F.A.; Murphy, E.A.; Willis, N.J.; Bataille, C.J.R.; Forman, R.; Heyer-Chauhan, N.; Marinič, B.; Sowood, D.J.C.; Wynne, G.M.; Else, K.J.; et al. Dihydrobenz[e][1,4] oxazepin-2(3H)-ones, a new anthelmintic chemotype immobilising whipworm and reducing infectivity in vivo. PLoS Negl. Trop. Dis. 2017, 11, e0005359. [CrossRef]

20. Partridge, F.A.; Forman, R.; Willis, N.J.; Bataille, C.J.R.; Murphy, E.A.; Brown, A.E.; Heyer-Chauhan, N.; Marinič, B.; Sowood, D.J.C.; Wynne, G.M.; et al. 2,4-Diaminothieno [3,2- $d$ ]pyrimidines, a new class of anthelmintic with activity against adult and egg stages of whipworm. PLoS Negl. Trop. Dis. 2018, 12, e0006487. [CrossRef]

21. Partridge, F.A.; Bataille, C.J.R.; Forman, R.; Marriott, A.E.; Forde-Thomas, J.; Häberli, C.; Dinsdale, R.L.; O'Sullivan, J.D.B.; Willis, N.J.; Wynne, G.M.; et al. Structural Requirements for Dihydrobenzoxazepinone Anthelmintics: Actions against Medically Important and Model Parasites: Trichuris muris, Brugia malayi, Heligmosomoides polygyrus, and Schistosoma mansoni. ACS Infect. Dis. 2021. [CrossRef]

22. Buckingham, S.D.; Partridge, F.A.; Poulton, B.C.; Miller, B.S.; McKendry, R.A.; Lycett, G.J.; Sattelle, D.B. Automated phenotyping of mosquito larvae enables high-throughput screening for novel larvicides and offers potential for smartphone-based detection of larval insecticide resistance. PLoS Negl. Trop. Dis. 2021, 15, e0008639. [CrossRef]

23. Clark, J.W. Rubitecan. Expert Opin. Investig. Drugs 2006, 15, 71-79. [CrossRef] [PubMed]

24. Liu, Y.-Q.; Li, W.-Q.; Morris-Natschke, S.L.; Qian, K.; Yang, L.; Zhu, G.-X.; Wu, X.-B.; Chen, A.-L.; Zhang, S.-Y.; Song, Z.-L.; et al. Perspectives on biologically active camptothecin derivatives. Med. Res. Rev. 2015, 35, 753-789. [CrossRef] [PubMed]

25. Zhang, L.; Zhang, Y.; He, W.; Ma, D.; Jiang, H. Effects of camptothecin and hydroxycamptothecin on insect cell lines Sf21 and IOZCAS-Spex-II. Pest. Manag. Sci. 2012, 68, 652-657. [CrossRef] [PubMed]

26. DeMilo, A.B.; Borkovec, A.B. Camptothecin, a potent chemosterilant against the house fly. J. Econ. Entomol. 1974, 67, 457-458. [CrossRef] [PubMed]

27. Liu, Y.-Q.; Yang, L.; Zhao, Y.-L.; Li, H.-Y. Synthesis of novel derivatives of camptothecin as potential insecticides. Pestic. Biochem. Physiol. 2010, 98, 219-223. [CrossRef]

28. Ma, J.; Tong, S.; Wang, P.; Liao, W.; Liu, H.; Zhang, L. Insecticidal activity of camptothecin against Nilaparvata lugens, Brevicoryne brassicae, and Chilo suppressalis. J. Econ. Entomol. 2010, 103, 492-496. [CrossRef]

29. Ong, S.-Q.; Jaal, Z. Larval age and nutrition affect the susceptibility of Culex quinquefasciatus (Diptera: Culicidae) to temephos. J. Insect Sci. 2018, 18. [CrossRef]

30. Pantazis, P.; Han, Z.; Chatterjee, D.; Wyche, J. Water-insoluble camptothecin analogues as potential antiviral drugs. JBS 1999, 6, 1-7. [CrossRef]

31. Liu, Y.-Q.; Liu, Z.-L.; Tian, X.; Yang, L. Anti-HSV activity of camptothecin analogues. Nat. Prod. Res. 2010, 24, 509-514. [CrossRef]

32. Wu, K.X.; Chu, J.J.-H. Antiviral screen identifies EV71 inhibitors and reveals camptothecin-target, DNA topoisomerase 1 as a novel EV71 host factor. Antivir. Res. 2017, 143, 122-133. [CrossRef] [PubMed]

33. Rialdi, A.; Campisi, L.; Zhao, N.; Lagda, A.C.; Pietzsch, C.; Ho, J.S.Y.; Martinez-Gil, L.; Fenouil, R.; Chen, X.; Edwards, M.; et al. Topoisomerase 1 inhibition suppresses inflammatory genes and protects from death by inflammation. Science 2016, 352 , aad7993. [CrossRef] [PubMed]

34. da Costa, C.F.; da Silva, A.V.; do Nascimento, V.A.; de Souza, V.C.; da Silva Monteiro, D.C.; Terrazaso, W.C.M.; dos Passos, R.A.; Nascimento, S.; Lima, J.B.P.; Naveca, F.G. Evidence of vertical transmission of Zika virus in field-collected eggs of Aedes aegypti in the Brazilian Amazon. PLoS Negl. Trop. Dis. 2018, 12, e0006594. [CrossRef] [PubMed]

35. Thangamani, S.; Huang, J.; Hart, C.E.; Guzman, H.; Tesh, R.B. Vertical Transmission of Zika Virus in Aedes aegypti Mosquitoes. Am. J. Trop Med. Hyg. 2016, 95, 1169-1173. [CrossRef] [PubMed]

36. Du, S.; Liu, Y.; Liu, J.; Zhao, J.; Champagne, C.; Tong, L.; Zhang, R.; Zhang, F.; Qin, C.-F.; Ma, P.; et al. Aedes mosquitoes acquire and transmit Zika virus by breeding in contaminated aquatic environments. Nat. Commun. 2019, 10, 1324. [CrossRef] 
37. Song, G.; Lee, E.M.; Pan, J.; Xu, M.; Rho, H.-S.; Cheng, Y.; Whitt, N.; Yang, S.; Kouznetsova, J.; Klumpp-Thomas, C.; et al. An integrated systems biology approach identifies the proteasome as a critical host machinery for ZIKV and DENV replication. Genom. Proteom. Bioinform. 2021. [CrossRef]

38. Staker, B.L.; Hjerrild, K.; Feese, M.D.; Behnke, C.A.; Burgin, A.B.; Stewart, L. The mechanism of topoisomerase I poisoning by a camptothecin analog. Proc. Natl. Acad. Sci. USA 2002, 99, 15387-15392. [CrossRef]

39. Gupta, E.; Vyas, V.; Ahmed, F.; Sinko, P.; Cook, T.; Rubin, E. Pharmacokinetics of orally administered camptothecins. Ann. N. Y. Acad. Sci. 2000, 922, 195-204. [CrossRef]

40. Herben, V.M.; Ten Bokkel Huinink, W.W.; Schellens, J.H.; Beijnen, J.H. Clinical pharmacokinetics of camptothecin topoisomerase I inhibitors. Pharm. World Sci. 1998, 20, 161-172. [CrossRef]

41. Herben, V.M.M.; ten Bokkel Huinink, W.W.; Beijnen, J.H. Clinical pharmacokinetics of topotecan. Clin.-Pharm. 1996, 31, 85-102. [CrossRef] [PubMed]

42. Burke, T.G.; Bom, D. Campthotecin design and delivery approaches for elevating anti-topoisomerase i activities in vivo. Ann. N. Y. Acad. Sci. 2000, 922, 36-45. [CrossRef] [PubMed]

43. Eddleston, M.; Chowdhury, F.R. Pharmacological treatment of organophosphorus insecticide poisoning: The old and the (possible) new. Br. J. Clin. Pharmacol. 2016, 81, 462-470. [CrossRef] [PubMed]

44. Li, F.; Jiang, T.; Li, Q.; Ling, X. Camptothecin (CPT) and its derivatives are known to target topoisomerase I (Top1) as their mechanism of action: Did we miss something in CPT analogue molecular targets for treating human disease such as cancer? Am. J. Cancer Res. 2017, 7, 2350-2394. [PubMed]

45. Morham, S.G.; Kluckman, K.D.; Voulomanos, N.; Smithies, O. Targeted disruption of the mouse topoisomerase I gene by camptothecin selection. Mol. Cell Biol. 1996, 16, 6804-6809. [CrossRef]

46. Zhang, C.X.; Chen, A.D.; Gettel, N.J.; Hsieh, T.S. Essential functions of DNA topoisomerase I in Drosophila melanogaster. Dev. Biol. 2000, 222, 27-40. [CrossRef]

47. Smit, M.R.; Ochomo, E.O.; Aljayyoussi, G.; Kwambai, T.K.; Abong'o, B.O.; Bousema, T.; Waterhouse, D.; Bayoh, N.M.; Gimnig, J.E.; Samuels, A.M.; et al. Human direct skin feeding versus membrane feeding to assess the mosquitocidal efficacy of high-dose ivermectin (IVERMAL Trial). Clin. Infect. Dis 2019, 69, 1112-1119. [CrossRef]

48. Dreyer, S.M.; Morin, K.J.; Vaughan, J.A. Differential susceptibilities of Anopheles albimanus and Anopheles stephensi mosquitoes to ivermectin. Malar. J. 2018, 17, 148. [CrossRef] [PubMed]

49. Richards, F.O. Upon entering an age of global ivermectin-based integrated mass drug administration for neglected tropical diseases and malaria. Malar. J. 2017, 16, 168. [CrossRef]

50. Ritz, C.; Baty, F.; Streibig, J.C.; Gerhard, D. Dose-Response Analysis Using R. PLoS ONE 2015, 10, e0146021. [CrossRef] 